Cómo citar / How to cite: Carrasco Castillo C. 2020. Las persecuciones contra cristianos de Decio y Valeriano. Dos conflictos generales previos a la gran persecución de Diocleciano. Lorente Muñoz, Mario. Murcia, 115 pp. ISBN: 9798651169825. Antigüedad y Cristianismo 37, 155-157. https:/doi.org/10.6018/ayc.458711

\title{
LAS PERSECUCIONES CONTRA CRISTIANOS DE DECIO Y VALERIANO. DOS CONFLICTOS GENERALES PREVIOS A LA GRAN persecución de Diocleciano. Lorente Muñoz, Mario. MURCIA, 2020, 115 PP. ISBN: 979-86-51 16-982-5
}

Recibido: 22-7-2020

Aceptado: 1-12-2020

Se nos presenta un libro en tapa blanda, con 115 páginas que, a través de un discurso narrativo, a la par que científica, nos acerca a un periodo convulso en el imperio romano. Nos enclavamos en una situación en la que Roma comienza a decaer, tanto en política interior como exterior, el cristianismo empieza a ser visto como un obstáculo y esto es lo que Lorente nos trata de reflejar y demostrar.

La publicación comienza dándonos una breve introducción de los motivos principales que le han llevado a escribir sobre el tema, entre ellos, su relevancia histórica, pues aporta información necesaria para poder entender el conflicto entre paganismo vs cristianismo y su gran importancia como antecedente de las persecuciones que llevaría a cabo Diocleciano, hecho que ha sido muy sustancial para la historiografía de la antigüedad tardía (4-5).

El autor se plantea un objetivo, al inicio de la obra, por el cual vamos a ver que se va a tratar de una publicación con un fin analíticodeductivo, algo que va a marcar su diálogo narrativo: "demostrar que las persecuciones de Decio y Valeriano fueron las dos primeras acciones persecutorias, sistemáticas y generales, llevadas a cabo por el Estado romano, contra el grupo social cristiano." Para poder hacer frente a esta demostración, Lorente va a emplear numerosas fuentes bibliográficas, pero entre todas ellas sobresalen tres que son de suma relevancia: las cartas de Cipriano de Cartago, las epístolas de las diócesis eclesiásticas y la
Historia Eclesiástica de Eusebio de Cesarea; son fuentes principales para conocer las relaciones del Estado romano con la Iglesia (6-9).

En el primer capítulo aparecen los motivos previos que llevaron a Roma a esta situación, se nos habla sobre el mismo tema, es decir, saber cómo eran las relaciones entre ambos bloques, vemos que serán relaciones líquidas, variarán con el tiempo. El autor también hace referencia a las persecuciones que hizo Nerón contra los cristianos, y para poder defender el objetivo planteado antes, nos muestra que a pesar de tratarse de persecuciones, estaban muy lejos de ser persecuciones sistemáticas y organizadas. También nos dice que los cristianos no trataron de atacar en ningún momento, figuras y creencias paganas, al contrario que el Estado romano. En el libro se nos dice que estas persecuciones previas tenían más que ver con "satisfacer un odio público, y no investigar un crimen" (13-16).

Más tarde, el autor nos habla de mártires de fechas anteriores al 250, como Perpetua y Felicidad. Al final de cada capítulo, se nos referenciará y hablará sobre la vida de mártires que tuvieron que pasar por las persecuciones, de esta manera, no solo se nos está ofreciendo información, fruto de una idea general, sino que también apela a datos concretos y objetivos, algo que da más veracidad a los hechos que se narran (19).

Antes de comenzar con la órbita a la cual gira toda la información del libro (las 
persecuciones de Decio y Valeriano), tenemos que hablar de Filipo el Árabe, un emperador que antecedió a Decio y que Lorente emplea como ejemplo, para ver la perfecta dualidad entre un emperador que vivió en paz con los cristianos, frente a otro que no lo hizo; que un hecho tan relevante como el de perseguir, o no, a un grupo social cambie en apenas un par de años, nos hace darnos cuenta de que el conflicto estaba más en las élites imperiales, ante el temor de perder su situación privilegiada, que en la sociedad romana; y eso es lo que entre líneas el autor nos da a entender. Filipo se mantuvo en una política pacífica con los cristianos, algo que cambiará totalmente con la persecución de Decio (20-21).

En el capítulo de Decio, autor, como ya hemos visto, comienza dándonos información acerca de sus referencias bibliográficas que le han permitido elaborar la información que se nos presenta.

Una vez que las tropas de Decio vencieron a las de Filipo, y el primero fue declarado emperador de Roma, comenzó la política “anticristiana”. Esta política comenzó obligando a toda la población a sacrificar a los ídolos paganos, además de renegar de las creencias que no tuvieran que ver con las paganas. Este hecho generó dos respuestas en el bloque cristiano, los que tuvieron que refugiarse y ser martirizados, y los que renegaron de la religión cristiana a cambio de salvar su vida, los apóstatas; estos últimos fueron luego mal vistos por la Iglesia (30-31).

La persecución de Decio movilizó a muchos cristianos que tuvieron que ser exiliados e hizo que tuvieran lugar varios concilios y se agitaran las élites cristianas, es aquí cuando surge la figura de Cipriano de Cartago, una de las fuentes principales empleadas por el autor. A todo esto, Lorente añade que la persecución de Decio no fue del todo homogénea, pues en lugares del norte de África, fue diferente a la que hubo en lugares cercanos a la capital; además que las consecuencias no eran las mismas para todas las gentes del imperio, dependía de su estatus social, honestior o humilior (31-33).
Para terminar, como es de costumbre, Lorente nos habla de casos de numerosos mártires que perecieron ante las persecuciones de este emperador, más de 10 casos donde se nos narran los hechos que sucedieron en su vida, de forma breve, el motivo de su martirio, cómo fue y donde; información que, a mi parecer, la veo muy interesante, a la par que relevante para reflejar hechos empíricos de lo que en Roma estaba ocurriendo (36-38).

En el siguiente capítulo tendremos las persecuciones de Valeriano; este va a ser el último emperador romano relevante que vamos a tratar, antes de llegar a las conclusiones. En él vamos a ver un cambio de mentalidad radical acerca de su actitud hacia el cristianismo. Valeriano llega del mismo modo que llega Decio al poder, derrotando al emperador reinante, y así lo referencia el autor. En un principio, Valeriano tendría la misma actitud que tuvo Filipo (hasta la aparición de Macrino), teniendo una política de paz con la Iglesia; hasta que sus consejeros le influenciaron para que continuara con las persecuciones, y así lo hizo. Sin embargo, la política de Valeriano contra los cristianos fue diferente a la del emperador que le antecedió; esta vez las persecuciones eran dirigidas hacia las élites cristianas, atajando el problema a través de aquellos a quienes les había tocado el papel de defenderlo y extenderlo (39-40).

A continuación, después de narrar varios hechos, más detenidamente, sobre la política de Valeriano, el autor nos va a enseñar el punto de vista del otro bando, sobre estas persecuciones. El martirio fue el gran problema para el Estado romano, pues los cristianos estaban preparados para morir, ya que su vida no estaba en la tierra, sino en el cielo; cuantos más cristianos se convertían en mártires, más fieles llegaban a la Iglesia, era algo imposible de parar. Es idóneo el ejemplo que tenemos al final de este capítulo donde se cuenta la vida de San Lorenzo y su martirio, pues refleja a la perfección la actitud que tuvieron los creyentes que se negaron a renunciar a su Dios y lucharon por conservar sus creencias (41-48). 
En cuanto a mi parecer, una vez leído detenidamente y contrastado el libro con las fuentes que el autor ofrecía; me parece que se trata de una investigación que resume bastante bien los hechos que se narraron a través de las fuentes primarias. Sobre su objeto de estudio, pienso que es uno fundamental para el estudio de la Antigüedad Tardía, pues se trata de un tema de mucho impacto en la sociedad romana, que además se enclava en un período tan notable para la historia, como es el de la Anarquía militar, y a través de una narración muy cuidada se nos relatan los hechos. Las referencias están adecuadamente seleccionadas $y$ al final del ensayo podemos ver una serie de anexos en los que se cita a Cipriano de Cartago con sus cartas, también aparecen fuentes iconográficas, numismáticas, arqueológicas...
Es decir, no solo vemos el gran interés del autor en reflejar la situación social a través del lenguaje que emplea, sino que al final, todo la realidad escrita se convierte en realidad visual. Un libro que puede gustarle a cualquier persona interesada en la Antigüedad Tardía o la evolución del cristianismo (69-115).

\author{
Carlos Carrasco Castillo \\ Universidad de Murcia, \\ Murcia, España \\ carlos.carrascoc@um.es \\ orcid.org/0000-0002-8508-4818
}


